\title{
Blood Pressure Levels and Stroke: J-curve Phenomenon?
}

\author{
Jolanta Malyszko • Paul Muntner • Jacek Rysz • \\ Maciej Banach
}

Published online: 25 October 2013

(C) The Author(s) 2013. This article is published with open access at Springerlink.com

\begin{abstract}
The blood pressure J-curve discussion has been ongoing for more than 30 years, yet there are still questions in need of definitive answers. On one hand, existing antihypertensive therapy studies provide strong evidence for J-curve-shaped relationships between both diastolic and systolic blood pressure and primary outcomes in the general hypertensive patient population, as well as in high-risk populations, including subjects with coronary artery disease, diabetes mellitus, left ventricular hypertrophy, and the elderly. On the other hand, we have very limited data on the relationship between systolic and diastolic blood pressure and stroke prevention. Moreover, it seems that this outcome is more a case of "the lower the better." Further large, welldesigned studies are necessary in order to clarify this issue, especially as existing available studies are observational, and randomized trials either did not have or lost statistical power and were thus inconclusive.
\end{abstract}

Keywords Blood pressure - Cerebrovascular event . Hypertension $\cdot \mathrm{J}$-curve relationship $\cdot$ Stroke

\footnotetext{
J. Malyszko

2nd Department of Nephrology and Hypertension with Dialysis Unit, Medical University, Bialystok, Poland

P. Muntner

Department of Epidemiology, School of Public Health, University of Alabama at Birmingham, Birmingham, AL, USA

J. Rysz

Department of Nephrology, Hypertension and Family Medicine, Medical University of Lodz, Lodz, Poland

M. Banach $(\square)$

Department of Hypertension, Medical University of Lodz,

Zeromskiego 113, 90-549 Lodz, Poland

e-mail: maciejbanach@aol.co.uk
}

\section{Introduction}

Stroke is a devastating and debilitating disease, currently the leading cause of disability and fourth leading cause of death $[1,2]$. Each year, approximately 16 million people worldwide are affected by stroke, and the estimated prevalence of stroke survivors is over 60 million [3]. The impact of stroke on quality of life, productivity, and the cost of health care is immense [4]. Stroke prognosis is influenced by a wide variety of factors, including age, stroke severity, stroke mechanism, infarct location, comorbid conditions, clinical findings, and related complications [5], and the medical community is obliged to identify risk factors and introduce preventive regimens [6]. Cerebrovascular disease is caused by one of several pathophysiologic processes involving the blood vessels of the brain, including: the intrinsic process related to the vessel, such as atherosclerosis, lipohyalinosis, inflammation, amyloid deposition, arterial dissection, developmental malformation, aneurysmal dilation, or venous thrombosis; an embolic process originating remotely (heart or extracranial circulation) and lodging in the intracranial vessel; inadequate cerebral blood flow due to decreased perfusion pressure or increased blood viscosity; and finally, rupture of a vessel in the subarachnoid space or intracerebral tissue [7]. It is therefore possible to differentiate between ischemic and hemorrhagic origin of cerebrovascular disease. The first three processes may result in transient brain ischemia (transient ischemic attack or TIA) or permanent brain infarction (ischemic stroke), whereas the last can lead to either subarachnoid hemorrhage or intracerebral hemorrhage (primary hemorrhagic stroke) [7, 8]. Approximately $80 \%$ of strokes are due to ischemic cerebral infarction and $20 \%$ to brain hemorrhage [1,8].

Hypertension is still the most common and leading risk factor for stroke [1, 7-9]. This includes isolated systolic hypertension, frequently observed in elderly patients $[10$, 
11]. As demonstrated in epidemiological and observational studies, there is a gradually increasing incidence of both coronary heart disease (CHD) and stroke as the blood pressure (BP) rises above 110/75 $\mathrm{mmHg}[7,12]$. In addition, both prior and current BP values are important risk factors for stroke [13]. It is somewhat difficult to prove a causal relationship between hypertension and stroke, as a rise in blood pressure could also be caused by other risk factors such as body weight gain and obesity that are often associated with dyslipidemia, glucose intolerance, and metabolic syndrome [14]. However, in assessing improved cardiovascular outcomes following antihypertensive therapy, it appears that elevated BP does play a causal role. The best evidence of the relationship between elevated BP and stroke comes from an overview of 14 hypertension treatment trials, where a long-term (mean 5 years ) $5-6 \mathrm{mmHg}$ decrease in normal diastolic blood pressure (DBP) was associated with a $35-40 \%$ reduction in stroke [8].

Advancing age has a major adverse impact on stroke morbidity, mortality, and long-term outcomes [15-18], as evidenced in both major and minor strokes. Older adults ( $>65$ years) have increased risk of death during the two months after stroke $[19,20]$. Age is similarly a risk factor for hypertension. Egan et al. [21] showed that hypertension is a common problem in elderly persons ( $>60-65$ years) in the U.S., reaching a prevalence as high as $60-80 \%$. In addition, one of the reports from the Framingham Heart Study indicated a progressive increase in the development of hypertension in patients over age $65(16 \%, 26 \%$, and $50 \%$ in the optimal, normal, and high-normal groups, respectively) [22]. A second report estimated that non-hypertensive individuals aged 5565 have a $90 \%$ lifetime risk of developing stage 1 hypertension (BP 140 to $159 / 90$ to $99 \mathrm{mmHg}$ ) and a $40 \%$ lifetime risk of developing stage 2 hypertension (BP $\geq 160$ / $\geq 100 \mathrm{mmHg}$ ) [23].

Severe uncontrolled hypertension is a major risk factor for intracranial hemorrhage, particularly in a young person admitted to the hospital with the acute onset of a focal neurologic deficit and BP greater than 220/120 mmHg. Song et al. [24] showed that each $20 \mathrm{mmHg}$ increase in systolic blood pressure (SBP) was associated with a much greater increased relative risk for hemorrhagic stroke than for ischemic stroke ( 3.18 vs. 2.23 ). Moreover, for $\mathrm{BP} \geq 180$ / $\geq 110 \mathrm{mmHg}$, the difference in relative risk between hemorrhagic and ischemic stroke subtypes was even more pronounced (28.83 vs. 9.56). Chronic hypertension, which promotes the formation of atherosclerotic lesions, is therefore the single-most important treatable risk factor for both thrombotic extracranial and intracranial large artery and penetrating artery disease $[24,25]$.

Approximately $60 \%$ of strokes in men and women of all ages are attributable to hypertension [1]. Hypertension is associated with an increased likelihood of subclinical or silent stroke, which in turn has been linked to an elevated risk of vascular dementia and recurrent stroke [26-28]. In addition to mean BP elevation, there is mounting evidence that visit-tovisit variability in SBP is an independent risk factor for stroke [29-31]. Conversely, the absence of a history of hypertension or present hypertension fundamentally reduces the likelihood of cerebrovascular disease [32]. In their 2011 guidelines, the American Heart Association (AHA) and American Stroke Association (ASA) recommended antihypertensive treatment for all patients with ischemic stroke and TIA who are more than 24 hours from symptom onset [33]. In patients with acute ischemic stroke, it is important not to lower BP too quickly. In addition, lifestyle modifications are recommended as part of the antihypertensive regimen, as these modifications have been associated with BP reduction [33]. Important modifications include weight loss; salt restriction; a diet rich in fruits, vegetables, and low-fat dairy products; regular aerobic physical activity; and limited alcohol consumption [33, 34]. The 2013 European Society of Hypertension (ESH) / European Society of Cardiology (ESC) Guidelines for the Management of Arterial Hypertension [35] recommend antihypertensive treatment in all hypertensive patients with a history of stroke or TIA, even when initial SBP is in the 140 $159 \mathrm{mmHg}$ range. They suggest a SBP goal of $<140 \mathrm{mmHg}$, although the SBP values for intervention and SBP goal may be somewhat higher in elderly hypertensives [35]. The guidelines also suggest a SBP treatment target of 150 $140 \mathrm{mmHg}$ in elderly patients under the age of 80 , although a target of less than $140 \mathrm{mmHg}$ may be considered in the fit elderly. The recommendation for hypertensive patients aged 80 and above is a target of $150-140 \mathrm{mmHg}$ [22]. These recommendations are in line with current AHA/American College of Cardiology Foundation (ACCF) guidelines (2011) [36].

\section{Search Strategy}

We searched using the MEDLINE (1966-October 2013), EMBASE and SCOPUS (1965-October 2013), and DARE (1966-October 2013) electronic databases. Abstracts from national and international cardiovascular meetings were searched as well. Where necessary, relevant authors were contacted to obtain further data. The main search terms were: blood pressure, hypertension, intensive (aggressive) hypotensive therapy, J-curve, stroke, therapy, and treatment.

\section{J-curve - Does it Exist in Stroke Patients?}

The J-curve phenomenon has been the subject of much discussion since it was first introduced by Stewart in 1979 with the presentation of the results of studies conducted in 169 
patients with severe arterial hypertension. A fivefold increased risk of myocardial infarction (MI) was noted in individuals who had achieved DBP reduction below $90 \mathrm{mmHg}$ over individuals with a BP range of 100-109 $\mathrm{mmHg}$ [35, 37]. Subsequent reports published in the 1980s confirmed these observations [38]. Subsequent detailed analysis has led to the conclusion that $\mathrm{BP}$ reduction may increase the risk of $\mathrm{CV}$ complications - similar to the effects of an excessive rise in BP - and this relationship takes on a characteristic $J$-curve shape $[37,39,40]$.

The Systolic Hypertension in the Elderly Program (SHEP) trial included 4,376 elderly patients (mean age 72 ) with a mean SBP/DBP of $170 / 77 \mathrm{mmHg}$ at baseline [10]. The patients were randomly assigned to antihypertensive therapy or placebo, and the goal of therapy was at least a $20 \mathrm{mmHg}$ reduction in SBP to a level below $160 \mathrm{mmHg}$. The patients were treated with chlortalidone, with atenolol or reserpine added when as necessary. BP attained was 143/68 $\mathrm{mmHg}$ in the treated group and $155 / 72 \mathrm{mmHg}$ in the placebo group [10]. Despite the low diastolic pressure attained by the treated group, this group had significantly better outcomes, including significantly lower incidence of stroke at 4 to 5 years $(5.5 \%$ vs. $8.2 \%$ with placebo) $[10,41]$. These benefits were noted in both men and women and in all age groups, including patients over the age of 80 . However, it was also noted that the achievement of low DBP was a factor predisposing to $\mathrm{CV}$ events - coronary artery disease (CAD) and other cardiovascular diseases (CVD) - in the actively treated patients $[10,41]$. The relative risk of composite CV events was significantly higher for DBP values greater than $70 \mathrm{mmHg}$, and close to a twofold increase for DBP greater than $55 \mathrm{mmHg}[10,41]$. Thus, a discrepancy was noted between cardiovascular and cerebrovascular outcomes.

The benefit of treating hypertension in extremely elderly patients was directly addressed in the Hypertension in the Very Elderly Trial (HYVET) [42••], in which the primary endpoint was fatal or nonfatal stroke. The trial included 3, 845 patients over 80 years of age (mean age 84 ) with a sustained SBP of at least $160 \mathrm{mmHg}$ (mean 173/91 mmHg), who were randomly assigned to either the thiazide diuretic indapamide or placebo. In addition, if they failed to meet the target $\mathrm{BP}$ of $150 / 80 \mathrm{mmHg}$, they randomly received either the angiotensin-converting enzyme inhibitor perindopril or placebo [42••]. At two years, the mean BP was $15.0 / 6.1 \mathrm{mmHg}$ lower with active therapy (approximately $143 / 78$ vs. $158 / 84 \mathrm{mmHg}$ ), similar to the values achieved in the SHEP trial [10,41]. Active therapy was associated with a significant reduction in fatal stroke (6.5 vs. $10.7 \%)$ and near significant reduction in all strokes $(12.4$ vs. $17.7 \%, p<0.06)$. All-cause mortality was reduced from 59.6/1,000 persons per year in the placebo group to $47.2 / 1,000$ persons per year in the active treatment group $[42 \bullet \bullet]$.
The Systolic Hypertension in Europe (Syst-Eur) trial [11] involved 4,695 patients over the age of 59 (mean age 70 years) with isolated systolic hypertension (mean initial-sitting BP of $174 / 86 \mathrm{mmHg}$ ). Active treatment consisted of nitrendipine or nitrendipine plus enalapril and hydrochlorothiazide if necessary [11]. The drop in BP was greater with active therapy ( $23 / 7$ vs. $13 / 2 \mathrm{mmHg}$ ). After 4 years, significant reductions were noted in stroke ( 7.9 vs. 13.7 total endpoints/1,000 patient years) and fatal and nonfatal cardiac endpoints [11]. It was estimated that treatment of 1,000 patients for 5 years would prevent 53 cardiovascular endpoints and 29 strokes. No Jcurve relationship was observed [11]. Subgroup analysis found that the mortality benefit increased significantly with a higher SBP at study entry, fell with increasing age [43], and was more pronounced in patients with diabetes mellitus [44].

In the treatment of elderly patients with isolated systolic hypertension, there are still no clear data indicating optimal levels of BP lowering. Studies are needed to provide guidance as to minimum SBP/DBP that can be tolerated. Analysis from the SHEP trial noted, on one hand, a clear benefit in reduced incidence of stroke in the active treatment group (lower-thebetter relationship), but on the other hand, found significant increases in cardiovascular events with diastolic blood pressure $\leq 60 \mathrm{mmHg}$ ( $J$-curve relationship) [45-49]. Only the subgroup analysis of elderly patients in the FEVER study showed a benefit for lowering SBP to levels below $140 \mathrm{mmHg}$ [50]. The FEVER study included almost 10,000 Chinese hypertensives, in whom cardiovascular outcomes were significantly reduced by more intense therapy (achieving a mean SBP of $138 \mathrm{mmHg}$ ), compared with less intense therapy (achieving a mean SBP of $142 \mathrm{mmHg}$ ). Significant reductions in stroke were found in uncomplicated hypertensives, in hypertensives with randomization $\mathrm{SBP}<153 \mathrm{mmHg}$, and in elderly hypertensives (mean age 69.5) $(-44 \%, p<0.001)$ when their SBP was lowered by more intense treatment [50]. Adding a small dose of a generic drug to achieve mean SBP values $<140 \mathrm{mmHg}$ was shown to prevent $5.2 \mathrm{CV}$ events in every 100 patients treated for 3.3 years. There was, again, a lower-the-better trend and no $J$-curve-shaped relationship [50].

Debate has often been contentious regarding the issue of BP in the elderly. Decades ago, it was thought that isolated systolic hypertension in the elderly was to be expected and that it was well-tolerated. In the observational Rotterdam study, an increase in risk of stroke began at DBP below $65 \mathrm{mmHg}$ [51]. These observations, however, are not conclusive proof of a cause-and-effect relationship between lower DBP and adverse cerebrovascular outcomes, particularly as the opposite is most often observed, which suggests a lower-the-better relationship. In a meta-analysis that included two trials of isolated systolic hypertension, a Jshaped curve relationship was noted in mortality outcome for both SBP and DBP but was not noted for cerebrovascular 
outcomes [52]. Moreover, the J-curve seen in treated and untreated patients was not specific for cardiovascular mortality. The authors concluded that the J-curve could probably be explained by poor health associated with lower blood pressure (poor tolerability) and not as an adverse effect of antihypertensive therapy [52].

In a recent study, Dorresteijn et al. [53] revisited the concept of BP and the J-curve in 5,788 symptomatic vascular disease patients enrolled in the Secondary Manifestations of Arterial Disease (SMART) study in a follow-up for the occurrence of new vascular events (i.e., myocardial infarction, stroke, or vascular death). SBP level was positively related to the occurrence of stroke $(p<0.01)$, but no nonlinearity was observed $(p=0.08)$ [53]. Therefore, low SBP level was not associated with increased occurrence of stroke. No association was found between mean baseline SBP level and occurrence of myocardial infarction. However, the relationship among SBP, DBP, and vascular mortality was J-shaped $(p=0.03)$. In this study, the effect of BP on vascular events was modified by presence or absence of recently diagnosed coronary artery disease, age ( $<65$ versus $\geq 65$ years), and pulse pressure $(<60$ versus $\geq 60 \mathrm{mmHg}$ ). Interestingly, elevated $\mathrm{BP}$ was not associated with increased morbidity and mortality in patients with recently diagnosed coronary artery disease $\geq 65$ years and having $>60 \mathrm{mmHg}$ pulse pressure. Importantly, low BP in these could be a symptom rather than a cause of disease. The authors suggested that BP below and above $143 / 82 \mathrm{mmHg}$ was an independent risk factor for recurrent vascular events in patients with established vascular disease [53]. In the observational analyses of the Treating to New Targets (TNT) trial, the nadir $\mathrm{BP}$, where the mortality rate was the lowest, was $146 / 81 \mathrm{mmHg}$ [54]. The study enrolled over 10,000 patients with a history of coronary artery disease. A nonlinear J-curve was not found for systolic blood pressure and stroke, although this relationship did exist between systolic blood pressure and vascular events [54].

In the REGARDS (REasons for Geographic and Racial Differences in Stroke) analysis, the researchers attempted to assess the optimal blood pressure level of 13,948 individuals located in the U.S. stroke belt (North and South Carolina, Georgia, Alabama, Mississippi, Tennessee, Arkansas, and Louisiana) $[55 \bullet \bullet, 56]$. Patients were divided according to baseline treated SBP levels: <120, 120-129, 130-139, 140149 , and $>150 \mathrm{mmHg}$. The primary outcomes were incident stroke, coronary heart disease, cardiovascular disease, and allcause mortality. For participants aged 55-64 and 65-75, no relationship between SBP and stroke incidence was observed. For participants $\geq 75$ years of age, stroke incidence increased across the full range of SBP. After multivariable adjustment, SBP $\geq 150 \mathrm{mmHg}$ was associated with an increased hazard ratio of stroke ( $p=0.091)$, but no increased risk was observed for SBP levels of 120-149 mmHg. When SBP was modeled as a continuous variable, lower SBP was associated with a decreased risk for stroke, especially among participants $\geq 75$ years of age (lower-the-better relationship) [55••]. However, the authors noted that considerable caution should be exercised for BP values $<120$, particularly $110 \mathrm{mmHg}$, especially for cardiovascular and coronary heart disease events as well as all-cause mortality (but not for stroke), because a Jcurve shaped relationship might be observed [55••]. The authors concluded that the results of the REGARDS cohort study generated a hypothesis that for all patients $>55$ years, the recommended level of SBP should be $<140 \mathrm{mmHg}$, with optimal values possibly in the $120-139 \mathrm{mmHg}$ range [55••].

This is a bold hypothesis to be extrapolated from the data, but it does highlight the need for continuing research in this area. The analysis was limited by the fact that only baseline BP measurements were available (2 measurements on a single occasion), leading to the potential misclassification of patients, and there was a relatively low number of stroke and CHD incidents in some subgroups. Despite these acknowledged limitations, the REGARDS trial holds tremendous value, especially as it included a large number (almost 14,000) of high-risk patients. The study also appears to indicate no J-curve association between these hypertension and stroke. Therefore, intensive hypertension therapy (with targeted $\mathrm{BP}<120 \mathrm{mmHg}$ ) should be the subject of further investigation $[55 \bullet \bullet]$.

Importantly, these results are strictly aligned with the results of the Action to Control Cardiovascular Risk in Diabetes (ACCORD) study [56]. ACCORD was a prospective randomized open-label study designed to evaluate the impact of treatment aimed at lowering SBP to $<120 \mathrm{mmHg}$ on the incidence of cardiovascular events (including stroke) in a high-risk group of diabetic patients $(\mathrm{n}=4,733$ patients in the hypertension arm) [56, 57]. The composite primary endpoint of the study was nonfatal MI/ stroke or death due to cardiovascular causes. Of the 4,733 patients enrolled in ACCORD BP, 2,362 were randomized to intensive treatment and 2,371 to standard therapy. After 1 year of treatment, the mean SBP was $119.3 \mathrm{mmHg}$ in the intensivetreatment arm and $133.5 \mathrm{mmHg}$ in the standard-therapy arm (difference: $14.2 \mathrm{mmHg}$ ), while the mean DBP values were 64.4 and $70.5 \mathrm{mmHg}$, respectively (difference: $6.1 \mathrm{mmHg}$ ) $[56,57]$. The primary endpoint of nonfatal MI/stroke or cardiovascular death occurred in 445 patients $(1.87 \%$ year in the intensive-treatment group, compared with $2.09 \%$ in standard-therapy group; $p=0.20$ ). There were also no significant differences in secondary endpoints between the studied groups; however, the incidence of stroke was significantly higher in the group receiving standard treatment $(0.53 \%$ vs. $0.32 \% ; p=0.01)$. A similar relationship was found for nonfatal stroke $(0.30 \%$ vs. $0.47 \% ; p=0.03)[56$, 57]. It is worth noting, however, that in patients from the group in which the SBP was lowered to $<120 \mathrm{mmHg}$, the incidence of treatment complications, such as orthostatic hypotension, hyperkalemia, or renal function impairment not 
requiring dialysis $\left(\mathrm{GFR}<30 \mathrm{ml} / \mathrm{min} / 1.73 \mathrm{~m}^{2}\right)$,increased significantly $(3.3 \%$ vs. $1.3 \%)[5,57]$. Interestingly, the results were quite similar to those observed in the Irbesartan Diabetic Nephropathy Trial (IDNT), where DBP $<85 \mathrm{mmHg}$ was associated with an increased trend in all-cause mortality, a significant increase in MI, but a decreased risk for stroke [58].

In summary, the ACCORD study suggested a lack of additional benefits from intensive BP reduction (apart from a significant effect on stroke incidence) in the group of patients with hypertension and Type 2 diabetes. It also indicated the potential negative aspects inherent in excessively intensive SBP lowering (possible J-curve mechanism). The research therefore illustrated the critical importance of defining the patient group in which significant BP reduction could be particularly dangerous and, conversely, identifying those at high risk of stroke who could benefit most from intensive hypotensive therapy [59].

Perhaps the many lingering questions surrounding the Jcurve will be answered only by the Systolic Blood Pressure Intervention Trial (SPRINT) [60], the results of which are expected to be available in 2018, and the Optimal Blood Pressure and Cholesterol Targets for Preventing Recurrent Stroke in Hypertensives (ESH-CHL-SHOT) study [61 ••], which begins recruiting patients in autumn of this year. The ESH-CHL-SHOT trial was designed by ESH and the Chinese Hypertension League (CHL) in order to finally resolve the dilemma between the "lower the better" and the "J-curve" hypotheses. In this regard, ESH and CHL have promoted a randomized trial comparing antihypertensive treatment strategies aimed at 3 different SBP targets in a defined group of hypertensives, those with recent stroke or TIA $[61 \bullet \bullet, 62]$.

\section{Conclusion}

Despite the many achievements in clinical and preventive medicine, stroke remains a major cause of disability and death. Epidemiological studies indicate a gradually increasing incidence of both coronary disease and stroke as the blood pressure rises above 110/75 $\mathrm{mmHg}$. Even with the increased data streams, however, optimal blood pressure levels have yet to be determined, particularly in the elderly. Recent studies do suggest that blood pressure should be reduced carefully in patients with hypertension and coronary artery disease, those with hypertension and diabetes, and those with hypertension and left ventricular dysfunction [39]. Blood pressure should not fall below 110-115/70-75 $\mathrm{mmHg}$, as this may be associated with more cardiovascular events. Data are generally lacking on the relationship between hypertension and cerebrovascular events. From the scant data that does exist, there appears to be linear rather than a J-shaped curvilinear relationship between these two factors (the lower-the-better relationship). Most of the data, however, come from observational studies or randomized controlled trials that are inadequately powered to determine a direct relationship between stroke and intensive BP lowering. It has been suggested that large interventional randomized controlled trials are needed to provide definitive answers to these questions [25, 63-65].

\section{Compliance with Ethics Guidelines}

Conflict of Interest Jolanta Malyszko, Paul Muntner, Jacek Rysz, and Maciej Banach declare that they have no conflict of interest. This review was written independently; no company or institution supported the authors financially or provided a professional writer. The authors have given talks, attended conferences, and participated in trials and advisory boards sponsored by various pharmaceutical companies.

Human and Animal Rights and Informed Consent This article does not contain any studies with human or animal subjects performed by any of the authors.

Open Access This article is distributed under the terms of the Creative Commons Attribution License which permits any use, distribution, and reproduction in any medium, provided the original author(s) and the source are credited.

\section{References}

Papers of particular interest, published recently, have been highlighted as:

•• Of major importance

1. Go AS, Mozaffarian D, Roger VL, Benjamin EJ, Berry JD, Borden WB, et al. American Heart Association Statistics Committee and Stroke Statistics Subcommittee. Heart disease and stroke statistics2013 update: a report from the American Heart Association. Circulation. 2013;127(1):e6-245.

2. Piotrowski G, Banach M, Gerdts E, Mikhailidis DP, Hannam S, Gawor R, et al. Left atrial size in hypertension and stroke. J Hypertens. 2011;29(10):1988-93.

3. Mukherjee D, Patil CG. Epidemiology and the global burden of stroke. World Neurosurg. 2011;76:S85.

4. Haley WE, Roth DL, Kissela B, Perkins M, Howard G. Quality of life after stroke: a prospective longitudinal study. Qual Life Res. 2011;20(6):799-806.

5. Brenner DA, Zweifler RM, Gomez CR, Kissela BM, Levine D, Howard G, et al. Awareness, treatment, and control of vascular risk factors among stroke survivors. J Stroke Cerebrovasc Dis. 2010;19(4):311-20.

6. Banach M, Mikhailidis DP, Kjeldsen SE, Rysz J. Time for new indications for statins? Med Sci Monit. 2009;15(12):MS1-5.

7. MacMahon S, Peto R, Cutler J, et al. Blood pressure, stroke, and coronary heart disease. Part 1, Prolonged differences in blood pressure: prospective observational studies corrected for the regression dilution bias. Lancet. 1990;335:765.

8. Collins R, Peto R, MacMahon S, et al. Blood pressure, stroke, and coronary heart disease. Part 2, Short-term reductions in blood pressure: overview of randomised drug trials in their epidemiological context. Lancet. 1990;335:827.

9. Banach M, Aronow WS. Hypertension therapy in the older adults-do we know the answers to all the questions? The status after publication of the ACCF/AHA 2011 expert consensus document on hypertension in the elderly. J Hum Hypertens. 2012;26(11):641-3. 
10. SHEP Cooperative Research Group. Prevention of stroke by antihypertensive drug treatment in older persons with isolated systolic hypertension. Final results of the Systolic Hypertension in the Elderly Program (SHEP). JAMA. 1991;265:3255.

11. Staessen JA, Fagard R, Thijs L, et al. Randomised double-blind comparison of placebo and active treatment for older patients with isolated systolic hypertension. The Systolic Hypertension in Europe (Syst-Eur) Trial Investigators. Lancet. 1997;350:757.

12. Lewington S, Clarke R, Qizilbash N, et al. Age-specific relevance of usual blood pressure to vascular mortality: a meta-analysis of individual data for one million adults in 61 prospective studies. Lancet. 2002;360:1903.

13. Seshadri S, Wolf PA, Beiser A, et al. Elevated midlife blood pressure increases stroke risk in elderly persons: the Framingham Study. Arch Intern Med. 2001;161:2343.

14. Barylski M, Małyszko J, Rysz J, Myśliwiec M, Banach M. Lipids, blood pressure, kidney - what was new in 2011? Arch Med Sci. 2011;7(6):1055-66.

15. Athyros VG, Giouleme O, Ganotakis ES, Elisaf M, Tziomalos K, Vassiliadis T, et al. Safety and impact on cardiovascular events of long-term multifactorial treatment in patients with metabolic syndrome and abnormal liver function tests: a post hoc analysis of the randomised ATTEMPT study. Arch Med Sci. 2011;7(5):796-805.

16. Feigin VL, Barker-Collo S, Parag V, et al. Auckland Stroke Outcomes Study. Part 1: gender, stroke types, ethnicity, and functional outcomes 5 years poststroke. Neurology. 2010;75:1597.

17. Knoflach M, Matosevic B, Rücker M, et al. Functional recovery after ischemic stroke-a matter of age: data from the Austrian Stroke Unit Registry. Neurology. 2012;78:279.

18. Howard VJ, Woolson RF, Egan BM, Nicholas JS, Adams RJ, Howard G, et al. Prevalence of hypertension by duration and age at exposure to the stroke belt. J Am Soc Hypertens. 2010;4(1):32-41.

19. Steiner T, Mendoza G, De Georgia M, et al. Prognosis of stroke patients requiring mechanical ventilation in a neurological critical care unit. Stroke. 1997;28:711.

20. Kammersgaard LP, Jørgensen HS, Reith J, et al. Short- and long-term prognosis for very old stroke patients. The Copenhagen Stroke Study. Age Ageing. 2004;33:149.

21. Egan BM, Zhao Y, Axon RN. US trends in prevalence, awareness, treatment, and control of hypertension, 1988-2008. JAMA. 2010;303:2043.

22. Vasan RS, Larson MG, Leip EP, et al. Assessment of frequency of progression to hypertension in non-hypertensive participants in the Framingham Heart Study: a cohort study. Lancet. 2001;358:1682.

23. Vasan RS, Beiser A, Seshadri S, et al. Residual lifetime risk for developing hypertension in middle-aged women and men: the Framingham Heart Study. JAMA. 2002;287:1003.

24. Song YM, Sung J, Lawlor DA, et al. Blood pressure, haemorrhagic stroke, and ischaemic stroke: the Korean national prospective occupational cohort study. BMJ. 2004;328:324.

25. Siebert J, Gutknecht P, Molisz A, Trzeciak B, Nyka W. Hemodynamic findings in patients with brain stroke. Arch Med Sci. 2012;8(2):371-4.

26. Vermeer SE, Longstreth Jr WT, Koudstaal PJ. Silent brain infarcts: a systematic review. Lancet Neurol. 2007;6:611.

27. Prabhakaran S, Wright CB, Yoshita M, et al. Prevalence and determinants of subclinical brain infarction: the Northern Manhattan Study. Neurology. 2008;70:425.

28. Das RR, Seshadri S, Beiser AS, et al. Prevalence and correlates of silent cerebral infarcts in the Framingham offspring study. Stroke. 2008;39:2929.

29. Rothwell PM, Howard SC, Dolan E, et al. Prognostic significance of visit-to-visit variability, maximum systolic blood pressure, and episodic hypertension. Lancet. 2010;375:895.

30. Rothwell PM. Limitations of the usual blood-pressure hypothesis and importance of variability, instability, and episodic hypertension. Lancet. 2010;375:938.
31. Bielecka-Dabrowa A, Aronow WS, Rysz J, Banach M. The rise and fall of hypertension: lessons learned from Eastern Europe. Curr Cardiovasc Risk Rep. 2011;5(2):174-9.

32. Mercando AD, Lai HM, Aronow WS, Kalen P, Desai HV, Gandhi K, et al. Reduction in atherosclerotic events: a retrospective study in an outpatient cardiology practice. Arch Med Sci. 2012;8(1):57-62.

33. Furie KL, Kasner SE, Adams RJ, et al. Guidelines for the prevention of stroke in patients with stroke or transient ischemic attack: a guideline for healthcare professionals from the American Heart Association/American Stroke Association. Stroke. 2011;42:227.

34. Seneff S, Wainwright G, Mascitelli L. Is the metabolic syndrome caused by a high fructose, and relatively low fat, low cholesterol diet? Arch Med Sci. 2011;7(1):8-20.

35. Mancia G, Fagard R, Narkiewicz K, Redón J, Zanchetti A, Böhm M, et al. Task Force Members. 2013 ESH/ESC Guidelines for the management of arterial hypertension: the Task Force for the management of arterial hypertension of the European Society of Hypertension (ESH) and of the European Society of Cardiology (ESC). J Hypertens. 2013;31:1281-357.

36. Aronow WS, Banach M. Ten most important things to learn from the ACCF/AHA 2011 expert consensus document on hypertension in the elderly. Blood Press. 2012;21(1):3-5.

37. Banach M, Michalska M, Kjeldsen SE, Małyszko J, Mikhailidis DP, Rysz J. What should be the optimal levels of blood pressure: does the J-curve phenomenon really exist? Expert Opin Pharmacother. 2011;12(12):1835-44.

38. Stewart IM. Relation of reduction in pressure to first myocardial infarction in patients receiving treatment for severe hypertension. Lancet. 1979;1:861-5.

39. Banach M, Aronow WS. Blood pressure j-curve: current concepts. Curr Hypertens Rep. 2012;14(6):556-66.

40. Cruickshank JM, Thorp JM, Zacharias FJ. Benefits and potential harm of lowering high blood pressure. Lancet. 1987;1(8533):581-4.

41. Kostis JB, Davis BR, Cutler J, et al. Prevention of heart failure by antihypertensive drug treatment in older persons with isolated systolic hypertension. SHEP Cooperative Research Group. JAMA. 1997;278:212.

42. • Beckett NS, Peters R, Fletcher AE, et al. Treatment of hypertension in patients 80 years of age or older. N Engl J Med. 2008;358:1887. The first randomized controlled trial which confirmed that we should have always treated elderly patients with hypertension, as it significantly improved cardiovascular and mortality outcomes.

43. Staessen JA, Fagard R, Thijs L, et al. Subgroup and per-protocol analysis of the randomized European Trial on Isolated Systolic Hypertension in the Elderly. Arch Intern Med. 1998;158:1681.

44. Tuomilehto J, Rastenyte D, Birkenhäger WH, et al. Effects of calcium-channel blockade in older patients with diabetes and systolic hypertension. Systolic Hypertension in Europe Trial Investigators. N Engl J Med. 1999;340:677.

45. Banach M, Rysz J. Current problems in hypertension and nephrology. Expert Opin Pharmacother. 2010;11(16):2575-8.

46. Gharipour M, Kelishadi R, Khosravi A, Shirani S, Masjedi M, Sarrafzadegan N. The impact of a community trial on the pharmacological treatment in the individuals with the metabolic syndrome: findings from the Isfahan Healthy Heart Program, 20012007. Arch Med Sci. 2012;8(6):1009-17.

47. Banach M, Kjeldsen SE, Narkiewicz K. Controversies in hypertension treatment. Curr Vasc Pharmacol. 2010;8(6):731-2.

48. Banach M, Hering D, Narkiewicz K, Mysliwiec M, Rysz J, Malyszko J. Lipids, blood pressure, kidney-what was new in 2012? Int J Pharmacol. 2012;8:659-78.

49. Somes GW, Pahor M, Shorr RI, et al. The role of diastolic blood pressure when treating isolated systolic hypertension. Arch Intern Med. 1999;159:2004.

50. Zhang Y, Zhang X, Liu L, Zanchetti A. Is a systolic blood pressure target $<140 \mathrm{mmHg}$ indicated in all hypertensives? Subgroup analyses 
of findings from the randomised FEVER trial. Eur Heart J. 2011;32: $1500-8$.

51. Vokó Z, Bots ML, Hofman A, et al. J-shaped relation between blood pressure and stroke in treated hypertensives. Hypertension. 1999;34: 1181.

52. Boutitie F, Gueyffier F, Pocock S, et al. J-shaped relationship between blood pressure and mortality in hypertensive patients: new insights from a meta-analysis of individual-patient data. Ann Intern Med. 2002;136:438.

53. Dorresteijn JA, van der Graaf Y, Spiering W, Grobbee DE, Bots ML, Visseren FL, et al. Relation between blood pressure and vascular events and mortality in patients with manifest vascular disease: Jcurve revisited. Hypertension. 2012;59:14-21.

54. Bangalore S, Messerli FH, Wun CC, Zuckerman AL, DeMicco D, Kostis JB, et al. J-curve revisited: an analysis of blood pressure and cardiovascular events in the Treating to New Targets (TNT) Trial. Eur Heart J. 2010;31:2897-908.

55. • Banach M, Bromfield S, Howard G, Howard VJ, Zanchetti A, Aronow WS, Ahmed A, Safford MM, Muntner P. Optimal blood pressure levels in elderly persons in the reasons for geographic and racial differences in stroke (REGARDS) cohort study. Clinical Trial Update Hot Line III Session: Updates on Risk and Outcome, European Society of Cardiology (ESC) Annual Congress 2013 in Amsterdam, 30 $0^{\text {th }}$ August $-4^{\text {th }}$ September 2013). Very important observational study made in the stroke belt area of US. It showed that for all patients above 55 we should always consider SBP level below $140 \mathrm{mmHg}$. It did not also show any Jcurve relation between SBP and stroke incidence, and rather linear association (the lower the better relation).

56. The ACCORD Study Group. Effects of Intensive Blood-Pressure Control in Type 2 Diabetes Mellitus. N Engl J Med. 2010;362:1575-85.

57. Action to Control Cardiovascular Risk in Diabetes Study Group, Gerstein HC, Miller ME, Byington RP, et al. Effects of intensive glucose lowering in type 2 diabetes. N Engl J Med. 2008;358:2545-59.
58. Berl T, Hunsicker LG, Lewis JB, et al. Impact of achieved blood pressure on cardiovascular outcomes in the Irbesartan Diabetic Nephropathy Trial. J Am Soc Nephrol. 2005;16:2170-9.

59. Nilsson PM. ACCORD and risk-factor control in Type 2 diabetes. $\mathrm{N}$ Engl J Med. 2010;362:1628-30.

60. Systolic Blood Pressure Intervention Trial (SPRINT). ClinicalTrials.gov Identifier: NCT01206062.

61. • Zanchetti A, Liu L, Mancia G, Parati G, Grassi G, Stramba-Badiale $\mathrm{M}$ et al. Blood Pressure and LDL-Cholesterol targets for prevention of recurrent strokes and cognitive decline in the elderly hypertensive patient. Design of the European Society of Hypertension - Chinese Hypertension League stroke in hypertension on optimal treatment (ESH-CHL-SHOT) randomized trial. J Hypertens 2014; (in press). It is important multinational and multicentre study, which may finally answer the question on the optimal blood pressure levels in patients after stroke/TIA, as well as the occurrence of J-curve shaped relation in this group of patients (or lack of such association).

62. Zanchetti A, L. Liu, Mancia G, Parati G, Grassi G, Stramba-Badiale $\mathrm{M}$ et al. Blood pressure and LDL-Cholesterol targets for prevention of strokes and cognitive decline in the hypertensive patient. Review of available trial evidence. J Hypertens 2014; (in press).

63. Makariou S, Liberopoulos E, Florentin M, Lagos K, Gazi I, Challa A, et al. The relationship of vitamin $\mathrm{D}$ with non-traditional risk factors for cardiovascular disease in subjects with metabolic syndrome. Arch Med Sci. 2012;8(3):437-43.

64. Michalska M, Rysz J, Pencina MJ, Zdrojewski T, Banach M. The knowledge and awareness of hypertension among patients with hypertension in Central Poland: A pilot registry. Angiology. 2013. doi:10.1177/0003319713489166.

65. Sundström J, Sheikhi R, Ostgren CJ, Svennblad B, Bodegård J, Nilsson PM, et al. Blood pressure levels and risk of cardiovascular events and mortality in type-2 diabetes: cohort study of 34009 primary care patients. J Hypertens. 2013;31(8):1603-10. 